\title{
Efficient and Reversible Removal of Boric Acid by Chitosan/Tannic Acid Functional Paper
}

\author{
Haodong Sun, ${ }^{\mathrm{a}}$ Nannan Xia, ${ }^{\mathrm{a}, *}$ Cheng Wu, ${ }^{\mathrm{b}}$ Keyin Liu, ${ }^{\mathrm{a}}$ Qin Wu, ${ }^{\mathrm{a}}$ Fangong Kong, ${ }^{\mathrm{a}}$ and \\ Shoujuan Wang ${ }^{\mathrm{a}, *}$
}

\begin{abstract}
It is important to remove excessive concentrations of boric acid from water because it can lead to environmental problems. However, current adsorbents are limited in separating boric acid from water due to their low desorption capability and poor selectivity for boric acid. In this study, the authors developed a functional cellulosic paper via crosslinking cellulose and tannic acid with chitosan to efficiently and reversibly remove boric acid from water. The adsorption capacity reached $769 \mathrm{mg} / \mathrm{m}^{2}$ according to the Langmuir model. The corresponding desorption rate of the chitosan/tannic acid-modified paper exceeded $80 \%$ in the whole flow rate region ranging from 15 to $250 \mathrm{~mL} / \mathrm{h}$. The reversible adsorption and desorption of boric acid were attributed to the formation and dissociation of the borate bond between the tannic acid and boric acid, respectively, at different $\mathrm{pH}$ values. This study improved the selectivity, batch adsorption, expensive carriers, and desorption difficulties of existing boric acid adsorption materials. This approach offers a new way to design highly efficient adsorption/desorption materials by constructing reversible chemical bonds for removal of other pollutants.
\end{abstract}

Keywords: Chitosan-tannic acid functional paper; Chitosan cross-linking; Reversible boric acid adsorption

Contact information: a: State Key Laboratory of Biobased Material and Green Papermaking, Key Laboratory of Pulp \& Paper Science and Technology of Shandong Province/Ministry of Education, Qilu University of Technology (Shandong Academy of Sciences), Jinan 250353, China; b: Xuancheng Product Quality Supervision and Inspection Institute, Xuancheng 242000, China;

*Corresponding authors: xianan00001@126.com; wshj@qlu.edu.cn

\section{INTRODUCTION}

Boric acid in surface water is mainly found in urban wastewater containing detergents and cleaning products, industrial effluents, and chemical products used in agriculture (García-Soto and Muñoz Camacho 2007). Boron is an essential micronutrient required for the normal growth of most plants; however, it can cause toxicity when above the normal range (Fujita et al. 2005). Nable et al. (1997) found that safe concentrations of boric acid in irrigation water are $0.3 \mathrm{mg} / \mathrm{L}$ for sensitive plants, 1 to $2 \mathrm{mg} / \mathrm{L}$ for semi-tolerant plants, and 2 to $4 \mathrm{mg} / \mathrm{L}$ for tolerant plants. Therefore, removing excessive boric acid from water is important.

Recently, a variety of separation and recovery technologies for boric acid from water have been developed such as reverse osmosis (Turek et al. 2007), ion exchange (Sahin 2002; Yilmaz et al. 2007; Kabay et al. 2009), concentration (Tural 2010), solvent extraction (Fortuny et al. 2014), membrane filtration (Bryjaka et al. 2009), electrodialysis (Yazicigil and Oztekin 2006), and adsorption (Miyazaki et al. 2008; Erto et al. 2014, 2017; Diaz de Tuesta et al. 2018; Liu et al. 2018). Adsorption is an effective method commonly 
used due to its low cost and easily available materials in wastewater disposal. Common adsorbents, such as a hydrotalcite-like compounds (Ferreira et al. 2006), neutralized red mud (Cengeloglu et al. 2007), waste sepiolite (Eozturki and Duygu 2004), magnetic particles (Liu et al. 2009), ferric oxide (Peak et al. 2003), fly ash (Ozturk and Kavak 2005), and activated carbon (Celik et al. 2008) have made some progress in removing boric acid from aqueous solutions. However, they are limited by the poor ionization of boric acid. This leads to difficult separation and low selectivity of the adsorbents (Celik et al. 2008; Miyazaki et al. 2008; Tural 2010; Nishihama et al. 2013).

Adsorbents have been reported for the selective adsorption of boric acid after complexing with the hydroxyl of boric acid; these are resistant to interference by the coexisting salts during adsorption (Meng et al. 2016; Lyu et al. 2017; Sun et al. 2018) However, most of these adsorbents mainly focus on the use of anion-exchange resin, activated carbon, and magnetic sorbents as carriers, and these carriers usually involve sophisticated preparation processes, complicated structures, and are expensive. This limits their application in the removal of boric acid.

There have been a few reports describing the adsorption ability of cellulose for boric acid. Cellulose is one of the most important natural polymers (Annadurai et al. 2002). It contains many - $\mathrm{OH}$ functional groups, making it easy to modify. Thus, cellulose can potentially be used as a carrier for boric acid adsorption. The adsorption of boric acid by cellulose fibers containing glucamine groups has been shown to have faster adsorption kinetics than conventional ion exchange resins (Inukai et al. 2004); however, this required complex modification of cellulose fibers and is not suitable for practical applications.

In this study, cellulosic paper with adsorption functions on boric acid was prepared with coniferous cellulosic fibers, chitosan, and tannic acid as the original paper materials, flocculant, and functional monomer, respectively, via simple papermaking. The boric acid could reversibly adsorb and desorb from the surface of the chitosan-tannic acid functional paper by formation and dissociation of borate with catechol at $\mathrm{pH}=10$ and $\mathrm{pH}=4$, respectively (Scheme 1). The adsorption ability was superior to most other studies (Erdem et al. 2013; Meng et al. 2016; Zhang et al. 2017).

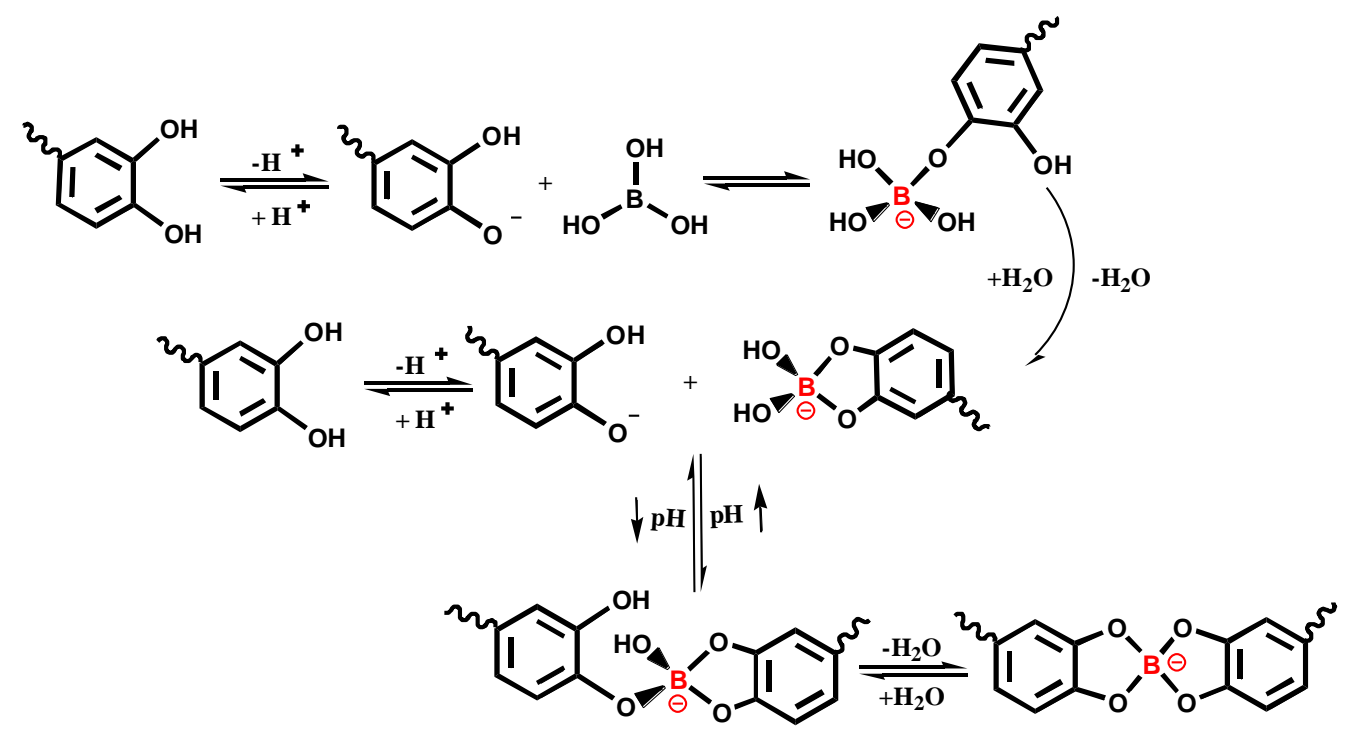

Scheme 1. Mechanism of adsorption and desorption 


\section{EXPERIMENTAL}

\section{Materials}

Tannic acid (analytical reagent, AR) was purchased from Aladdin Industrial Corporation (Shanghai, China); chitosan (AR), azomethine-H (AR), ascorbic acid (AR), ammonium acetate (AR), ethylene diaminetetraacetic acid (EDTA, AR), acetic acid (AR), and boric acid (AR) were purchased from Sigma-Aldrich (Shanghai, China) and used as received without further purification. Polyacrylamide (PAM, AR, $M_{\mathrm{w}}=5$ million, solids content $\geq 90 \%$ ) was purchased from Tianjin Kemiou Chemical Co., Ltd. (Tianjin, China), cationic polyacrylamide (CPAM, AR, $M_{\mathrm{w}}=12$ million, effective substance $\geq 99 \%$ ) was purchased from Gongyi Baolai Water Treatment Material Factory (Zhengzhou, China). The tannic acid and boric acid were prepared in different concentrations according to the experimental requirements. Needle bush pulp was obtained from Shandong Sun Paper Group (Yanzhou, Shandong, China).

\section{Papermaking process}

Needle bush pulp board (moisture content 8.0\%), $500 \mathrm{~g}$, was torn into pieces with a diameter of 4 to $5 \mathrm{~cm}$ and then stirred after addition of $23 \mathrm{~L}$ of water in a pulper (Shandong Sun Paper Group, Yanzhou, China) until the beating degree reached $35 \pm 2{ }^{\circ} \mathrm{SR}$. The prepared pulp was dehydrated for $2 \mathrm{~min}$ in a dehydrator to form granules less than $5 \mathrm{~mm}$ in diameter.

The pulp (20 g) was dissociated in a fiber disintegrator (Shandong Sun Paper Group, Yanzhou, China) (4000 r/min) at $75.6 \%$ moisture content, and then the tannic acid $(30 \mathrm{~mL}, 100 \mathrm{~g} / \mathrm{L})$ and chitosan $(100 \mathrm{~mL}, 1 \mathrm{~g} / \mathrm{L})$ were added to this pulp. Sheets were made by pouring the pulp slurry into the bowl of a paper-sheet former followed by draining the slurry through a metallic wire. The wet paper sheet was dried at $60^{\circ} \mathrm{C}$ to obtain the desired chitosan/tannic acid-modified paper (Fig. 1). The basis weight of the paper sheet was approximately $188 \mathrm{~g} / \mathrm{m}^{2}$. Therein, the content of tannic acid in paper sheet was calculated using Eq. 1,

$$
F(\%)=\left[\left(m_{1}-m_{2} \times \omega\right) / m\right] \times 100
$$

where $F$ is the content $(\%)$ of tannic acid in paper, $m_{1}$ is the weight $(\mathrm{g})$ of the modified paper by tannic acid, $m_{2}$ is the weight ( $\mathrm{g}$ ) of the pulp, $\omega$ is the concentration (\%) of pulp, and $m$ is the addition amount $(\mathrm{g})$ of tannic acid.

Meanwhile, the comparative samples (original paper, chitosan-modified paper, and tannic acid-modified paper) were prepared similar to the above method and the different samples are shown in Fig. 1(e through h).

In addition, the loss rate of tannic acid was considered in the process of adsorption or desorption according to Eq. 2,

$$
L(\%)=\left[\left(m_{3}-m_{4}\right) / m_{t}\right] \times 100
$$

where $L$ is the loss rate $(\%)$ of tannic acid, $m_{3}$ is the weight $(\mathrm{g})$ of the modified paper by tannic acid, $m_{4}$ is the weight $(\mathrm{g})$ of the paper after adsorption or desorption, and $m_{\mathrm{t}}$ is the weight $(\mathrm{g})$ of the tannic acid in the paper. 


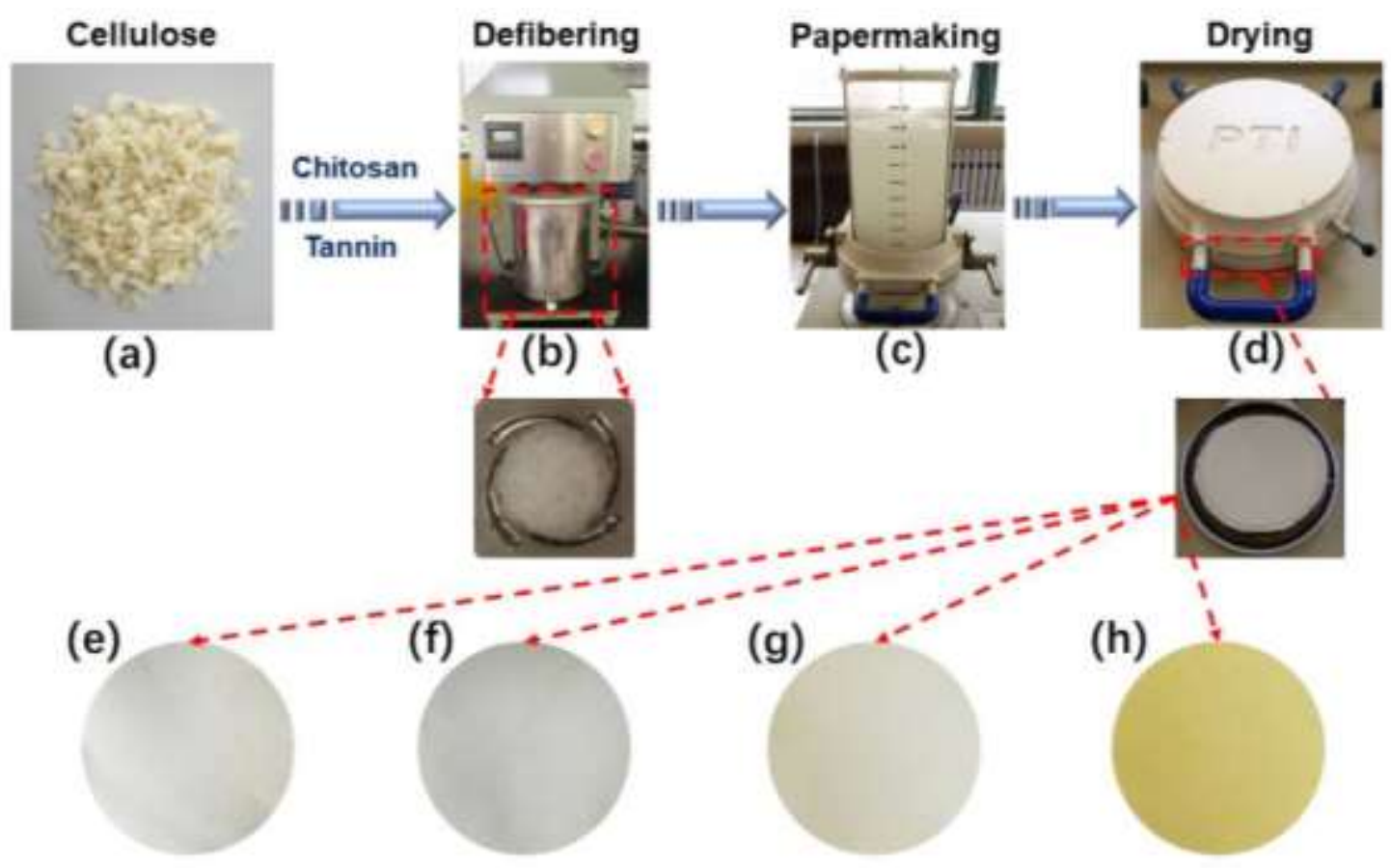

Fig. 1. Process of papermaking: (a) Cellulosic fibers obtained via disassembling the pulp board; (b) Cellulosic fibers dispersed evenly in water via defibering in the disintegrator; (c) Cellulosic fiber slurry was placed on a papermaking machine for paper sheet forming; (d) The paper was dried in a dryer; (e) Original paper; (f) chitosan-modified paper; (g) tannic acid-modified paper; and (h) chitosan/tannic acid-modified paper

\section{Methods}

Fourier transform infrared (FTIR) spectra were recorded using a Bruker Vertex70 FTIR (Karlsruhe, Germany) spectrophotometer between 600 and $4000 \mathrm{~cm}^{-1}$ with a resolution of $4 \mathrm{~cm}^{-1}$ using attenuated total reflectance (ATR) spectroscopy. The effect of tannic acid on the transmittance of paper was measured using an Agilent Cary5000 UVVis-NIR spectrophotometer (Agilent Technologies, Santa Clara, CA, USA). The ultraviolet-visible (UV-Vis) spectra were collected to monitor a boronic ester bond. Therein, the preparation process of different paper for FTIR and UV-Vis measurement is shown in Fig. 1, and was tested directly through the ATR and integrating-sphere accessory. The aim was to observe the form of chemical bonds in the solid samples. The thermal stability of the original paper and modified paper were performed using a TA Instruments TGA Q50 (TA Instruments, New Castle, DE, CA, USA) with a heating rate of $10{ }^{\circ} \mathrm{C} / \mathrm{min}^{-}$ ${ }^{1}$ in nitrogen. The changes of surface topography of the paper before and after modification were obtained using a Coxemem-30 PLUS scanning electron microscope (SEM) (Coxem Co., Ltd., Daejeon, Korea).

The mechanical properties of the modified paper and saturated paper were examined using an electronic tensile machine XLW(B) (Labthink Instruments Co., Ltd., Jinan, China) and tear strength machine SLY-1000 (Hangzhou Qingtong \& Boke Automation Technology Co., Ltd., Hangzhou, China); the test methods followed the GB/T 22898 (2008) and GB/T 455 (2002) standards. The peristaltic pump (30 W) was used to control the flow rate of boric acid solution during all adsorption processes. 


\section{Adsorption}

Cellulosic fibers were combined with tannic acid via electrostatic interactions, and hydrogen bonds were formed based on the cationic and hydroxyl groups in the chitosan and tannic acid (Fig. 2b) (Tang et al. 2003; Sauperl et al. 2015; Xiao and Hu 2017). Adsorption experiments were performed to evaluate the adsorption performance of the modified paper and the original paper. All adsorption experiments were performed with continuous sample introduction systems at $25^{\circ} \mathrm{C}$. First, the paper sheet was cut into round pieces approximately $5 \mathrm{~cm}$ in diameter and spread in a glass funnel. Next, the boric acid was dissolved in $50 \mathrm{~mL}$ deionized water at the desired concentration of boric acid, and the solution was adjusted with $0.5 \mathrm{~mol} / \mathrm{L} \mathrm{NaOH}$ solution until $\mathrm{pH}=10$. Finally, the boric acid solution was slowly trickled into the glass funnel fitted with a paper sheet, and the flow rate $(40$ to $120 \mathrm{~mL} / \mathrm{h}$ ) was controlled by adjusting the peristaltic pump (Fig. 2a). After adsorption, the concentration of the boric acid was determined via an UV-Vis spectrophotometer (UV-VIS-NIR Agilent Cary5000; Agilent Technologies Inc., Santa Clara, CA, USA) at $412 \mathrm{~nm}$ with azomethine-H as a colorimetric reagent according to the method described in the literature (Goldberg 2005; Liu et al. 2009). The amount of boric acid adsorbed onto the paper was calculated using Eq. 3,

$$
A=\left[V\left(C_{0}-C\right) / 1000 G\right]-A_{0}
$$

where $A$ is the adsorption capacity $\left(\mathrm{mg} / \mathrm{m}^{2}\right)$ of the modified paper to boric acid (this mainly highlights the function of the tannic acid), $A_{0}$ is the adsorption capacity $\left(\mathrm{mg} / \mathrm{m}^{2}\right)$ of the original paper to boric acid, $C_{0}$ and $C$ are the boric acid concentrations $(\mathrm{mg} / \mathrm{L})$ in the solutions before and after adsorption, respectively, $V$ is the volume $(\mathrm{mL})$ of the solutions, and $G$ is the area $\left(\mathrm{m}^{2}\right)$ of the paper.

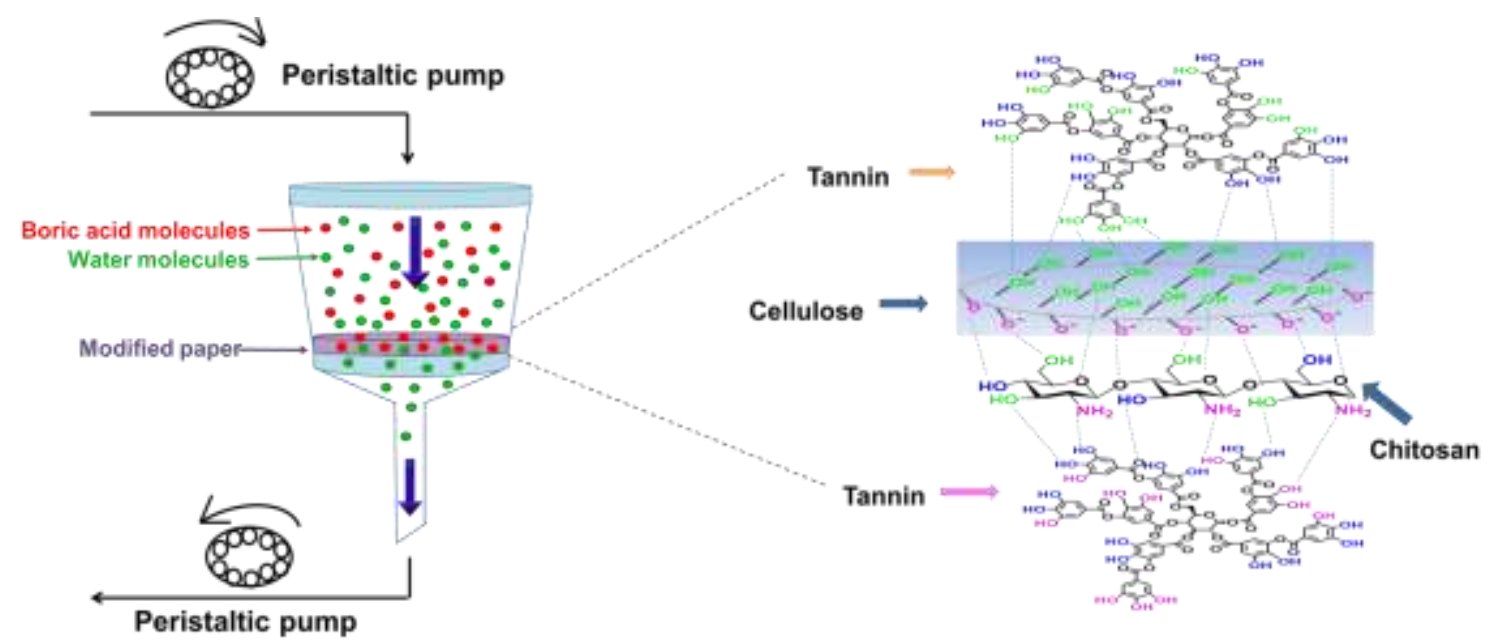

Fig. 2. Boric acid adsorbed on cellulosic paper: (a) Adsorption process of boric acid on paper and (b) Binding mechanism of tannic acid and cellulosic paper

\section{Adsorption model}

The relationship between the boric acid adsorption capacity and the residual boric acid concentration in solution was described by the Langmuir and Freundlich isotherm adsorption models, respectively. Therein, the monolayer adsorption model came from the work of Langmuir (Ozturk and Kavak 2005), which is given as Eq. 4:

$$
Q_{e}=\frac{Q_{m} C_{e}}{1 / b+C_{e}}
$$


The constants $Q_{\mathrm{m}}$ and $b$ are characteristics of the Langmuir equation and can be determined from the linearized form of Eq. 5,

$$
\frac{C_{e}}{Q_{e}}=\frac{C_{e}}{Q_{m}}+\frac{1}{b Q_{m}}
$$

where $C_{\mathrm{e}}$ is the concentration of boric acid $(\mathrm{mg} / \mathrm{L})$ at equilibrium, $Q_{\mathrm{m}}$ is the monolayer capacity of the paper $\left(\mathrm{mg} / \mathrm{m}^{2}\right)$, and $b$ is the Langmuir adsorption constant $(\mathrm{L} / \mathrm{mg})$. The Freundlich isotherm is an empirical equation that has been used to describe adsorption on heterogeneous surfaces. The model is formulated as Eq. 6:

$$
q_{e}=k C_{e}^{1 / n}
$$

The equation may be linearized by taking the logarithm of both sides of the equation, and the linear form of the Freundlich isotherm can be given as follows,

$$
\log q_{e}=\log k+\frac{1}{n} \log C_{e}
$$

where $C_{\mathrm{e}}$ is the concentration $(\mathrm{mg} / \mathrm{L})$ at equilibrium, $k$ is the adsorption capacity $\left(\mathrm{mg} / \mathrm{m}^{2}\right)$, and $n$ is an empirical parameter.

\section{Desorption}

A total of $50 \mathrm{~mL}$ deionized water was adjusted with $0.5 \mathrm{~mol} / \mathrm{L} \mathrm{HCl} \mathrm{until} \mathrm{pH}=4$. The aqueous solution was then slowly trickled into the glass funnel fitted with boric acidadsorbed paper, and the flow rate $(40,60,80,100$ and $120 \mathrm{~mL} / \mathrm{h})$ of this water solution was controlled by a peristaltic pump. The desorption rate of the boric acid was calculated by Eq. 8 ,

$$
E(\%)=\left(C_{\mathrm{t}} V_{\mathrm{t}} / 1000 A\right) \times 100
$$

where $C_{\mathrm{t}}$ denotes detected concentration $(\mathrm{mg} / \mathrm{L})$ of boric acid in the desorption solution, $V_{\mathrm{t}}$ is the volume $(\mathrm{mL})$ of the desorption solutions, and $A$ is the adsorption capacity $(\mathrm{mg})$ of the modified paper for boric acid.

\section{Paper recycling}

After the modified paper was desorbed, the authors performed the papermaking process as described in Figs. 1a through 1d (defibering, papermaking, and drying) to obtain the recycled paper. The adsorption experiments used continuous sample introduction systems at $25^{\circ} \mathrm{C}$ as the adsorption substrate.

All adsorption and desorption processes were repeated three times.

\section{RESULTS AND DISCUSSION}

In the first set of experiments, the effect of chitosan, cationic polyacrylamide, and PAM on the flocculation of tannic acid was investigated. Figure 3 shows that the addition of $2 \%$ chitosan into paper could lead to the optimum flocculation of tannic acid $(20 \%)$ surpassing the control conditions, i.e. CPAM and PAM. This implies that the $-\mathrm{OH}$ and $\mathrm{NH}_{2}$ of chitosan could promote the flocculation of tannic acid by formation of both hydrogen bonds and electrostatic interactions in the system. This was superior to PAM and CPAM with only H-bonding or electrostatic interactions (Figs. 2b and 3), respectively. Additionally, the flocculation of tannic acid on the paper sheet gradually increased with 
increasing flocculation time under stirring (Fig. 4). The flocculation tended to be stable when the flocculation time reached $4 \mathrm{~h}$. This indicated that the hydrogen bonding and electrostatic interaction among cellulose, tannic acid, and chitosan were nearly saturated after $4 \mathrm{~h}$ of flocculation. Thus, $2.0 \%$ chitosan could promote the best flocculation of tannic acid on the paper at flocculation time of $4 \mathrm{~h}$ at $20 \%$ tannic acid.

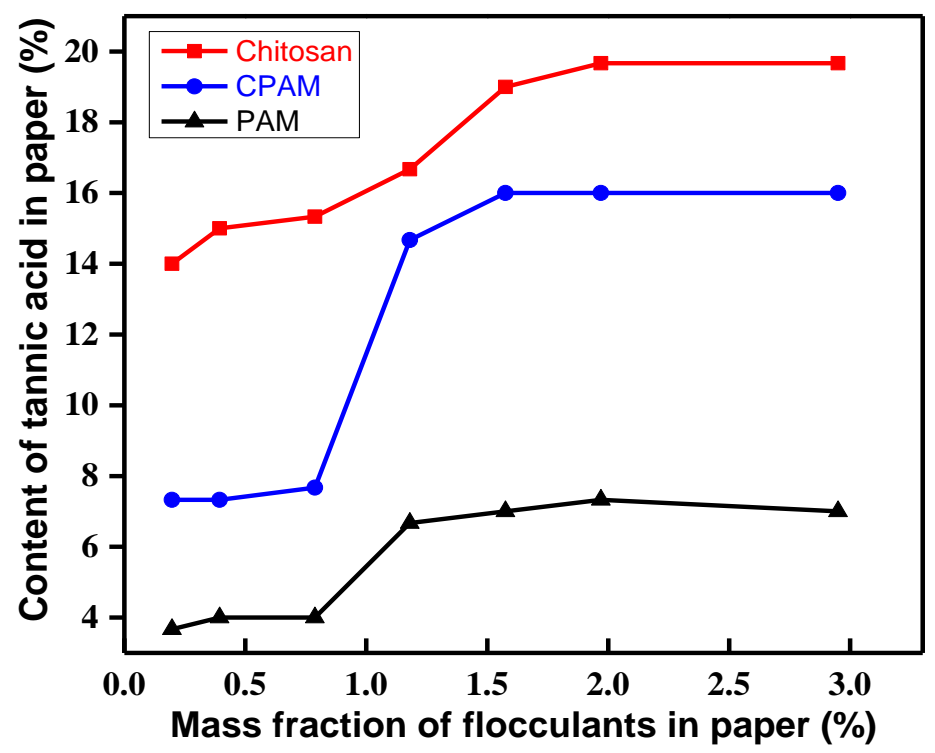

Fig. 3. Effect of different flocculants (chitosan, cationic polyacrylamide (CPAM), and polyacrylamide (PAM)) on the content of tannic acid in paper

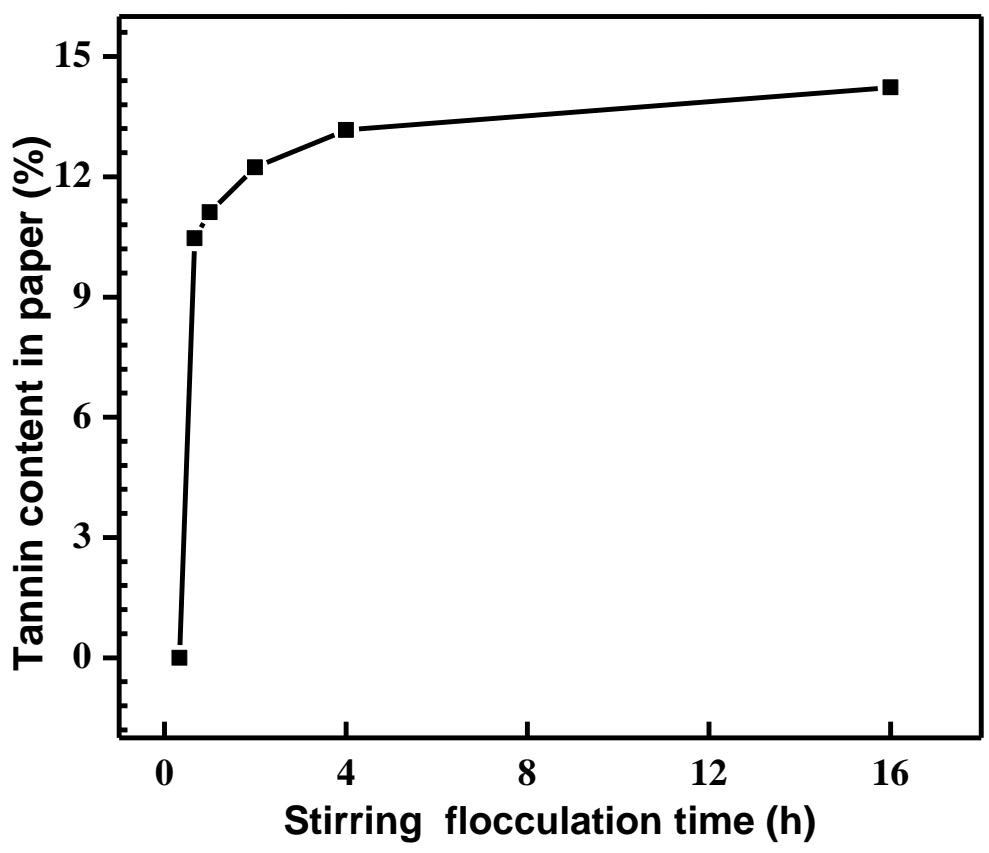

Fig. 4. Effect of contact time on the content of tannic acid in the paper when the mass fraction of chitosan in paper is $0.2 \%$ 
The microstructure of the original and chitosan/tannic acid-modified paper was further investigated using SEM. The cellulosic fiber density of the chitosan/tannic acidmodified paper was higher than the original paper (Fig. 5a and 5b), which demonstrated that both the tannic acid and chitosan played important roles in crosslinking the paper; chitosan had better flocculation effects.
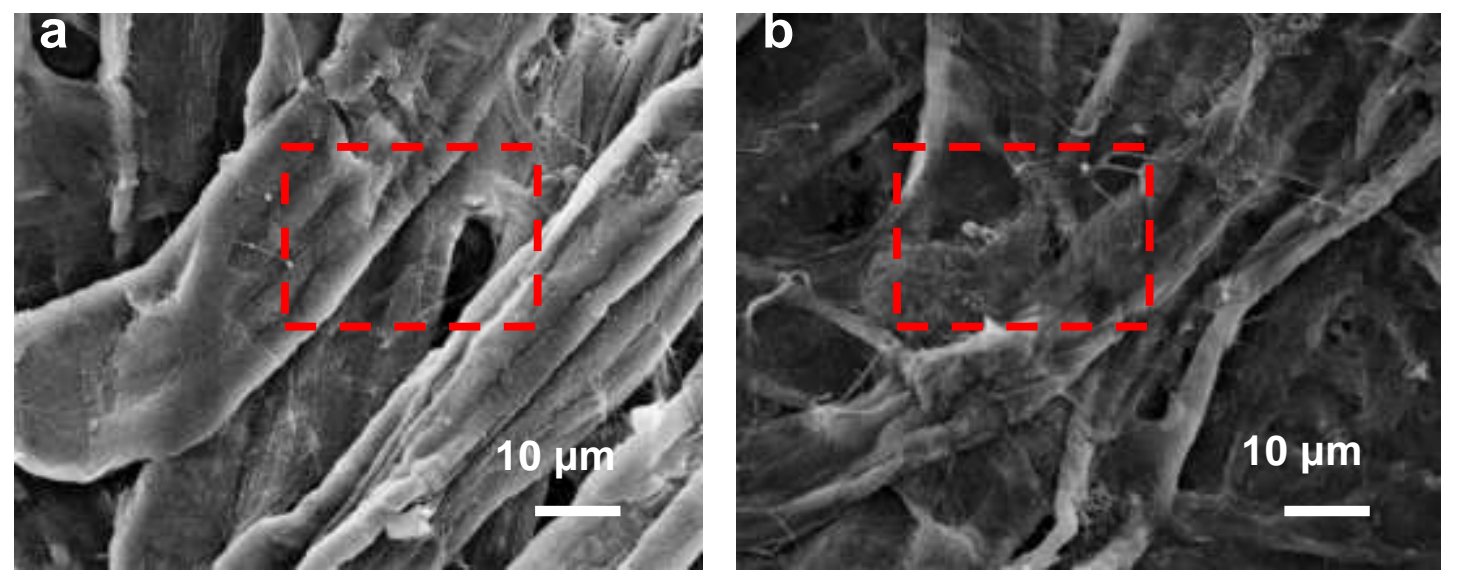

Fig. 5. SEM morphology of (a) original paper and (b) chitosan/tannic acid-modified paper. The red labeling demonstrated that the modified paper had a higher binding density compared to the original paper.

To verify the presence of hydrogen bonding and electrostatic interaction among cellulosic fibers, chitosan, and tannic acid, the thermal stability of the original and chitosan/tannic acid-modified papers was studied using TGA. Figure 6 shows that the chitosan/tannic acid-modified paper had better thermal stability as confirmed by the higher initial decomposition temperature than that of the original paper. Furthermore, the maximum decomposition temperature of chitosan/tannic acid-modified paper was also superior to that of the original paper. These results indicated that there was hydrogen bonding and electrostatic interaction among the cellulosic fibers, chitosan, and tannic acid, which could improve the thermal stability of chitosan/tannic acid-modified paper. 


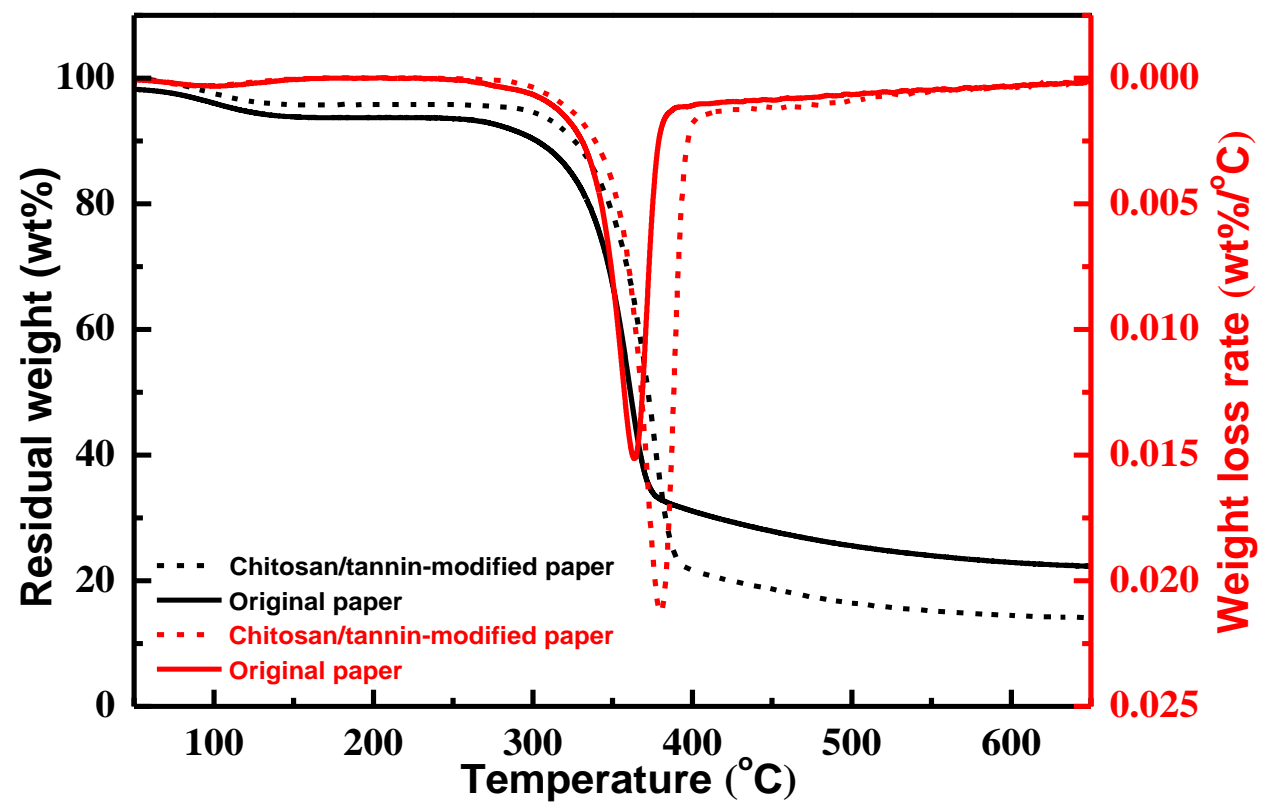

Fig. 6. TG and TGA curves of original paper and chitosan/tannic acid-modified paper

To further confirm that tannic acid was successfully flocculated by chitosan on the chitosan/tannic acid-modified paper, FTIR spectra were investigated. Figure 7 compares the original paper, chitosan-modified paper, tannic acid-modified paper, and the chitosan/tannic acid-modified paper. There were two obvious peaks at $1688 \mathrm{~cm}^{-1}$ and 1600 $\mathrm{cm}^{-1}$ corresponding to the stretching vibrations of $-\mathrm{C}=\mathrm{O}$ and $-\mathrm{C}=\mathrm{C}-$ of the benzene ring in the tannic acid, respectively. In comparison, the tannic acid-modified paper did not have vibration peaks at $1688 \mathrm{~cm}^{-1}$ and $1600 \mathrm{~cm}^{-1}$, which was ascribed to the low content of tannic acid.

The UV-Vis spectra of the original and modified papers were also investigated. In principle, when the tannic acid was loaded in the paper, the characteristic adsorption peak of the tannic acid would be obvious via UV-Vis spectrophotometer. As shown in Fig. 8a, both the original and chitosan-modified papers showed a poor absorption peak at approximately $300 \mathrm{~nm}$. However, an enhanced absorption peak at approximately $300 \mathrm{~nm}$ originating from the catechol of the tannic acid was observed for the chitosan/tannic acidmodified papers, clearly indicating that the tannic acid was loaded onto paper. Moreover, the chitosan/tannic acid-modified paper showed the lowest transmittance among the original and other modified papers (Fig. 8b). The results of FTIR and UV-Vis spectra demonstrated that chitosan could noticeably promote flocculation of tannic acid on the chitosan/tannic acid-modified paper. The absorption peak of the tannic acid-modified paper shifted to $320 \mathrm{~nm}$ versus the chitosan/tannic acid-modified paper. This was mainly attributed to the formation of $o$-benzoquinone due to oxidation of the catechol in tannic acid. This implied that hydrogen bond formation and electrostatic interaction among cellulosic fibers, chitosan, and tannic acid could stabilize the catechol of the tannic acid, which was beneficial to the adsorption of boric acid by the formation of the borate bond. These characteristics further confirmed the reliability of Fig. $2 b$. 


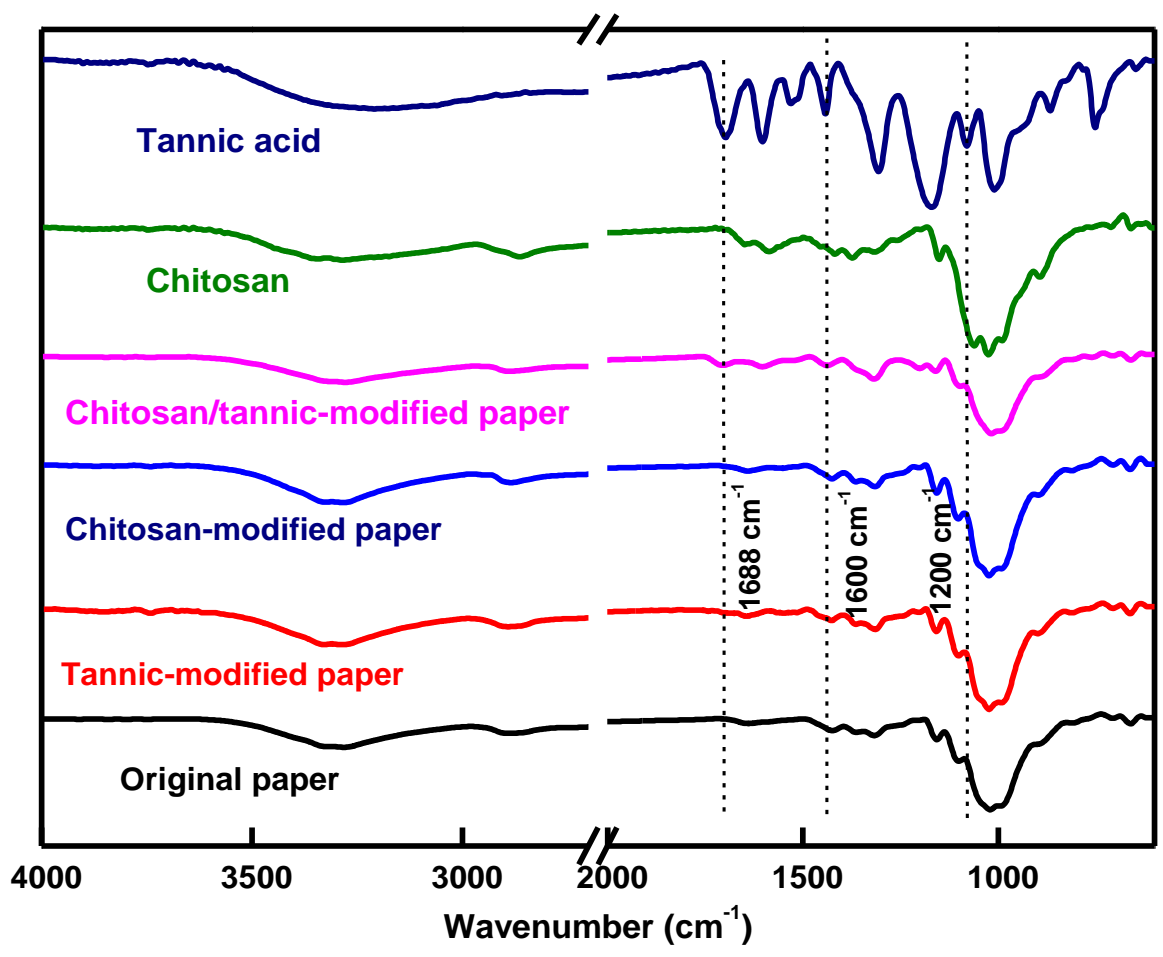

Fig. 7. FTIR spectra of original and modified papers.
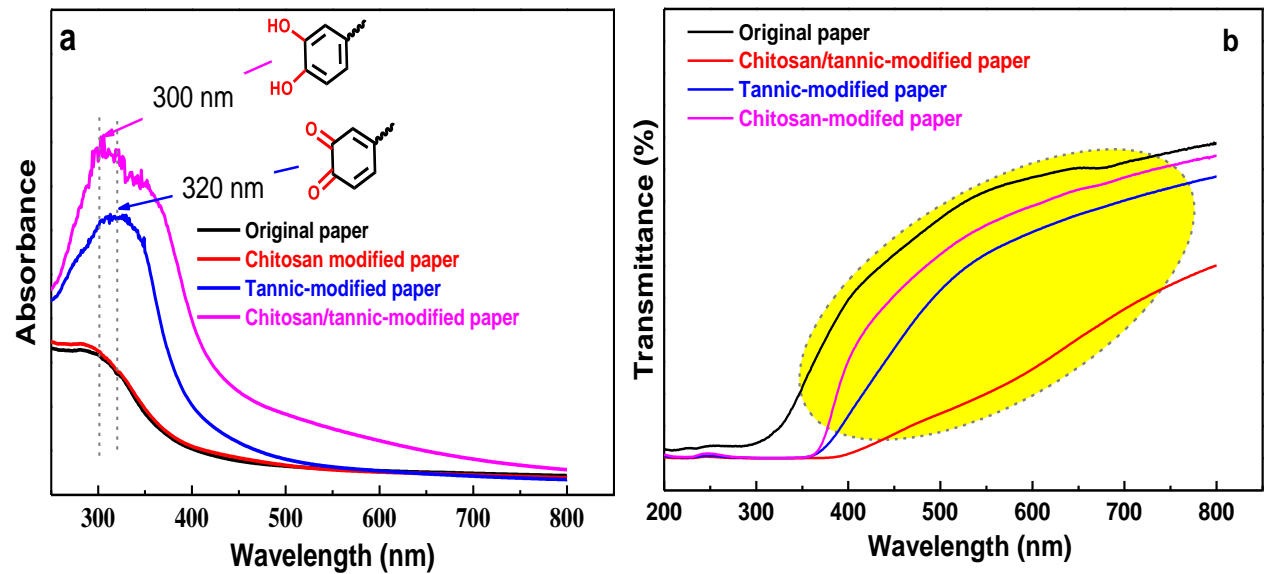

Fig. 8. The (a) UV-Vis reflection and (b) transmission spectra of different paper

\section{Adsorption}

A continuous flow-through setup based on the modified paper was designed to adsorb the boric acid (Fig. 9a). The use of a flow-through microreactor model for boric acid adsorption was more practical model because it would overcome the issues associated with batch operation in practical water treatment. As proved by others, the catechol of tannic acid reacted with $\mathrm{H}_{3} \mathrm{BO}_{3}$ to form borates at a basic $\mathrm{pH}$, which was dissociated at an acidic pH (Vatankhah-Varnoosfaderani et al. 2014; Xia et al. 2016). Thus, the effects of $\mathrm{pH}$ on boric acid adsorption will not be discussed; in this paper, the authors mainly discuss the effect of velocity and concentration on boric acid adsorption. 
The effect of velocity on boric acid adsorption was first investigated at a $\mathrm{pH}$ of 10 . The results in Fig. 9a clearly indicate that the adsorption capacity of all modified papers for boric acid gradually decreased with increasing flow rate of boric acid solution. Moreover, the adsorption capacity of chitosan/tannic acid-modified paper for boric acid reached a maximum at $40 \mathrm{~mL} / \mathrm{h}$. This implied that the high velocity of boric acid solution would not be beneficial to the full contact between the boric acid and catechol of tannic acid on the surface of the chitosan/tannic acid-modified paper. Thus, boric acid did not effectively react with catechol in tannic acid. In addition, the chitosan/tannic acid-modified paper showed the best adsorption for boric acid across the entire velocity region of 40 to $120 \mathrm{~mL} / \mathrm{h}$ among all three samples. This was attributed to the higher tannic acid content in the chitosan/tannic acid-modified paper. In this regard, chitosan could considerably improve the tannic acid loading on the paper via the formation of hydrogen bonds and electrostatic interactions that subsequently enhanced boric acid adsorption.

The adsorption capacity of chitosan/tannic acid-modified paper for boric acid at different concentrations was further investigated at $\mathrm{pH}=10$. Figure $9 \mathrm{~b}$ shows that the adsorption capacity increased with increasing initial concentration of boric acid. This might have been because the high concentration of boric acid increased the contact and reaction possibility with catechol in the tannic acid.

The corresponding adsorption model of boric acid was also established. Figure 9 (c and d) and Table 1 show that the adsorption model of boric acid on chitosan/tannic acidmodified paper was more consistent with the Langmuir isotherm plot as verified by the better linear correlation coefficient. The constants for the isotherm were obtained based on the slope and intercept of the plots of the isotherm (Fig. 9c). The monolayer adsorption capacity $\left(Q_{0}\right)$ and adsorption equilibrium constant (b) were $769 \mathrm{mg} / \mathrm{m}^{2}$ and 116 for the Langmuir isotherm, respectively. This demonstrated that the modified paper had a high adsorption capacity for boric acid. 

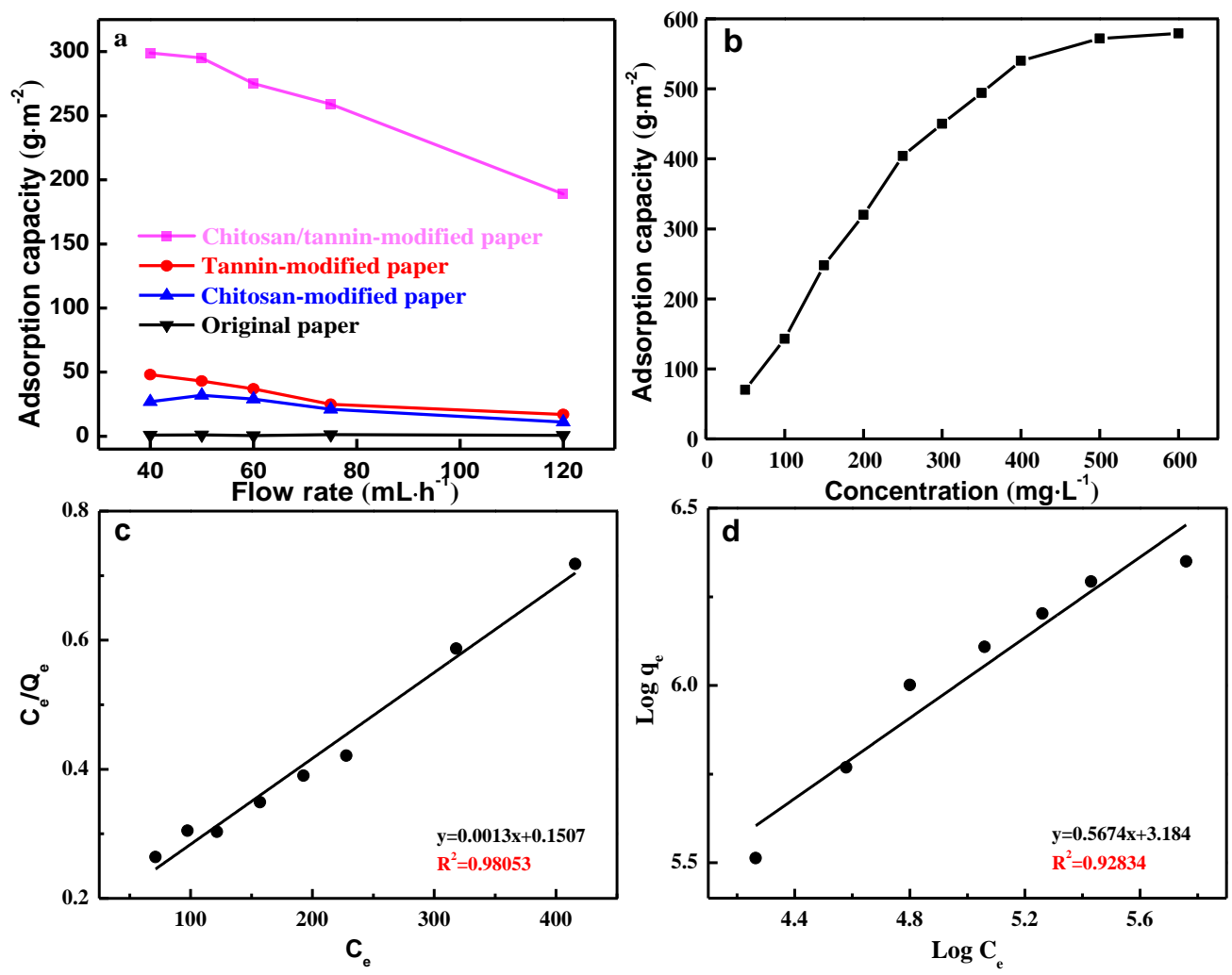

Fig. 9. (a) Effect of the flow rate on boric acid adsorption at $200 \mathrm{mg} / \mathrm{L}$ and $\mathrm{pH}=10$; (b) Effect of initial concentration of boric acid on the adsorption capacity at a velocity of $40 \mathrm{~mL} / \mathrm{h}$ and $\mathrm{pH}=10$; (c) Langmuir isotherm plot; and (d) Freundlich isotherm plot for adsorption of boric acid on the chitosan/tannic acid-modified paper surface. According to the equation of $t=\mathrm{Q} / \mathrm{CV}$, the saturated adsorption time was calculated to be $96 \mathrm{~h} / \mathrm{m}^{2}$.

Table 1. Adsorption Isotherm Parameters for Boric Acid Adsorption on Modified Paper

\begin{tabular}{|c|c|c|c|c|c|}
\hline \multicolumn{2}{|c|}{ Langmuir Isotherm Constants } & \multicolumn{3}{c|}{ Freundlich Isotherm Constants } \\
\hline$B\left(\mathrm{~L} / \mathrm{m}^{2}\right)$ & $Q_{0}\left(\mathrm{mg} / \mathrm{m}^{2}\right)$ & $\mathrm{R}^{2}$ & $K_{\mathrm{F}}\left(\mathrm{mg} / \mathrm{m}^{2}\right)\left(\mathrm{L} / \mathrm{m}^{2}\right)$ & $\mathrm{n}$ & $\mathrm{R}^{2}$ \\
\hline 115.923 & 769.23 & 0.981 & 24.143 & 1.762 & 0.928 \\
\hline
\end{tabular}

As described earlier, the cellulose fiber was combined with tannic acid via physical interactions. This probably resulted in the tannic acid loss during the adsorption of boric acid. Thus, there was likely a loss of tannic acid on the modified paper after multiple rounds of boric acid adsorption. Figure 10a shows that the loss rate of tannic acid in the chitosan/tannic acid-modified paper was only approximately $7 \%$, even though the boric acid solution volume per unit area of paper was $16 \mathrm{~L} / \mathrm{m}^{2}$. Moreover, the lower volume of boric acid solution per unit area would result in an obviously greater loss of tannic acid. Thus, the tannic acid could be stable on the surface of chitosan/tannic acid-modified paper when the boric acid solution volume per unit area on the paper sheet was controlled. The authors note that the tannic acid-modified paper showed a much higher loss rate of tannic acid than that of the chitosan/tannic acid-modified paper and reached 35\%. These results demonstrated that chitosan could stabilize tannic acid on the modified paper surface via the formation of hydrogen bonds and electrostatic interactions. This agreed well with the TGA 
and UV-Vis results. Although the saturated paper strength decreased after adsorption, the higher strength was restored after drying (Table 2).

Table 2. Mechanical Properties of the Modified Paper and Saturated Paper

\begin{tabular}{|c|c|c|}
\hline Paper Type & Tensile Strength $(\mathrm{kN} / \mathrm{m})$ & Tearing Strength $\left(\mathrm{mN} \cdot \mathrm{m}^{2} / \mathrm{g}\right)$ \\
\hline Modified paper & 11.6 & 17.981 \\
\hline Saturated paper & 1.39 & 10.466 \\
\hline Dried saturated paper & 8.08 & 14.205 \\
\hline
\end{tabular}

\section{Desorption}

Good desorption capacity is important for reusability of the adsorption material. The desorption capacity of chitosan/tannic acid-modified paper for boric acid was investigated at different velocities under optimal adsorption conditions. The desorption capacity of chitosan/tannic acid-modified paper for boric acid exceeded $80 \%$ in the whole flow rate region of 15 to $250 \mathrm{~mL} / \mathrm{h}$ (Fig. 10b), which confirmed the desorption stability. Therefore, the chitosan/tannic acid-modified paper could achieve the ideal desorption of boric acid at a controlled flow rate.
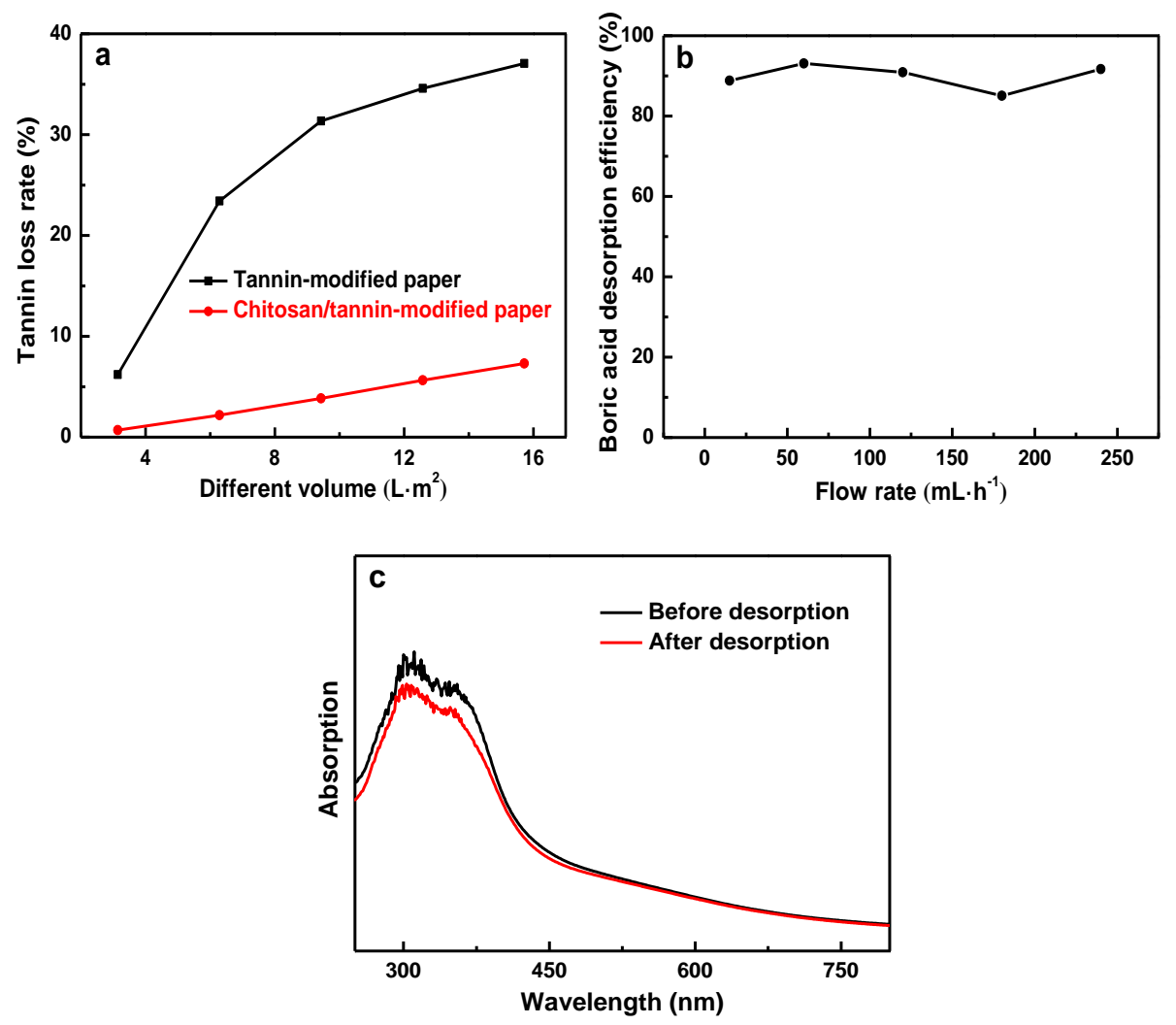

Fig. 10. (a) Tannic acid loss rate on the modified paper. Paper weight: $188 \mathrm{~g} / \mathrm{m}^{2}$, tannic acid content: 20\%; Desorption of boric acid on the chitosan/tannic acid-modified paper: (b) Effect of flow rate on boric acid desorption efficiency; and (c) UV-Vis absorbance changes before and after desorption of boric acid

Furthermore, the UV-Vis spectra showed that the absorption peak of catechol of tannic acid in the chitosan/tannic acid-modified paper was still located at approximately 
$300 \mathrm{~nm}$ and exhibited a smaller difference before and after the desorption of boric acid (Fig. 10c). All of these results demonstrated that the desorption process had less influence on the loss of tannic acid in the chitosan/tannic acid-modified paper. In addition, as shown in Fig. 11a and b, compared with Fig. 9a and b, the adsorption capacity and desorption efficiency of recycled paper on boric acid decreased slightly. This showed that the modified paper had a higher capacity for renewal (Fig. 11).
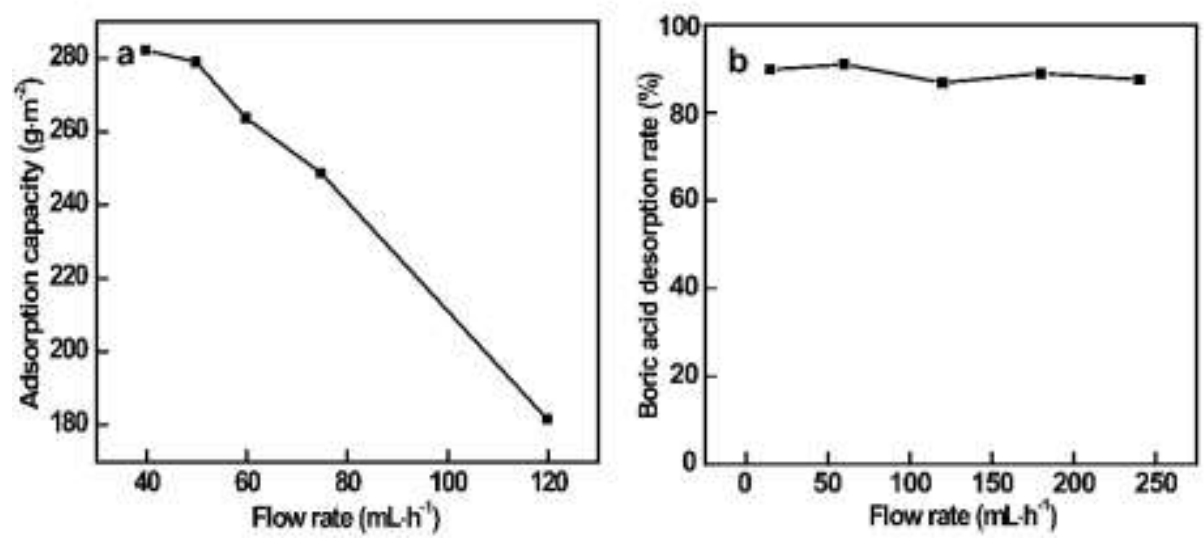

Fig. 11. (a) Effect of the flow rate on adsorption of recycled paper. (b) Effect of the flow rate on boric acid desorption rate of recycled paper

\section{CONCLUSIONS}

1. A new functional paper for boric acid adsorption was prepared by cross-linking cellulosic fibers and tannic acid with chitosan. The chitosan/tannic acid-modified paper showed excellent adsorption capacity for $\mathrm{H}_{3} \mathrm{BO}_{3}$ via borate formation between catechol of tannic acid and $\mathrm{H}_{3} \mathrm{BO}_{3}$, with less activity loss under alkaline conditions.

2. Moreover, this material exhibited good and stable desorption ability for boric acid in acidic solution due to dissociation of the borate bond between tannic acid and boric acid. The maximal adsorption capacity of the chitosan/tannic acid-modified paper can reach $769 \mathrm{mg} / \mathrm{m}^{2}$, as calculated by the Langmuir adsorption model.

3. The high adsorption capacity and excellent stability of desorption were ascribed to the formation of $\mathrm{H}$-bonding networks and electrostatic interactions originating from $-\mathrm{OH}$ and $-\mathrm{NH}_{2}$ among cellulosic fibers, chitosan, and tannic acid. This chitosan/tannic acidmodified paper material is reusable and has future industrial applications.

\section{ACKNOWLEDGMENTS}

The authors are grateful for financial support from the Natural Science Foundation of Shandong (ZR2018BEM026, ZR2017LEM009), the National Natural Science Foundation of China (Grant Nos. 31570566, 31600472, and 31800499), the Key Research and Development Program of Shandong Province (No. 2017GSF17130), the Foundation of Guangxi Key Laboratory of Clean Pulp \& Papermaking and Pollution Control of China (KF201717). The authors also thank the National Key R\&D Program of China (No. 
2017YFB0308000) and the Joint Research Fund for fellowship support and Qilu University of Technology (Shandong Academy of Sciences) (No. 2017BSH2010) for their support.

\section{REFERENCES CITED}

Annadurai, G., Juang, R. S., and Lee, D. J. (2002). "Use of cellulose-based wastes for adsorption of dyes from aqueous solutions," Journal of Hazardous Materials 92(3), 263-274. DOI: 10.1016/S0304-3894(02)00017-1

Bryjaka, M., Wolskaa, J., Sorokoa, I., and Kabayb, N. (2009). “Adsorption-membrane filtration process in boron removal from first stage seawater RO permeate," Desalination 241(1-3), 127-132. DOI: 10.1016/j.desal.2008.01.062

Celik, Z. C., Can, B. Z., and Kocakerim, M. M. (2008). "Boron removal from aqueous solutions by activated carbon impregnated with salicylic acid," Journal of Hazardous Materials 152(1), 415-422. DOI: 10.1016/j.jhazmat.2007.06.120

Cengeloglu, Y., Tor, A., Arslan, G., Ersoz, M., and Gezgin, S. (2007). "Removal of boron from aqueous solution by using neutralized red mud," Journal of Hazardous Materials 142(1-2), 412-417. DOI: 10.1016/j.jhazmat.2006.08.037

Diaz de Tuesta, J. L., Silva, A. M. T., Faria, J. L., and Gomes, H. T. (2018). "Removal of Sudan IV from a simulated biphasic oily wastewater by using lipophilic carbon adsorbents," Chemical Engineering Journal 347, 963-971. DOI: 10.1016/j.cej.2018.04.105

Eozturki, N., and Duygu, K. (2004). "Boron removal from aqueous solutions by adsorption on waste sepiolite and activated waste sepiolite using full factorial design," Adsorption 10(3), 245-257. DOI: 10.1023/B:ADSO.0000046361.62180.c6

Erdem, P., Bursali, E. A., and Yurdakoc, M. (2013). "Preparation and characterization of tannic acid resin: Study of boron adsorption," Environmental Progress and Sustainable Energy 32(4), 1036-1044. DOI: 10.1002/ep.11703

Erto, A., Bortone, I., Di Nardo, A., Di Natale, M., and Musmarra, D. (2014). "Permeable adsorptive barrier (PAB) for the remediation of groundwater simultaneously contaminated by some chlorinated organic compounds," Journal of Environmental Management 140, 111-119. DOI: 10.1016/j.jenvman.2014.03.012

Erto, A., Chianese, S., Lancia, A., and Musmarra, D. (2017). "On the mechanism of benzene and toluene adsorption in single-compound and binary systems: Energetic interactions and competitive effects," Desalination and Water Treatment 86, 259-265. DOI: $10.5004 / d w t .2017 .20712$

Ferreira, O.P., De Moraes, S. G., Duran, N., Cornejo, L., and Alves, O. L. (2006). "Evaluation of boron removal from water by hydrotalcite-like compounds," Chemosphere 62(1), 80-88. DOI: 10.1016/j.chemosphere.2005.04.009

Fortuny, A., Coll, M. T., Kedarib, C. S., and Sastrec, A. M. (2014). "Effect of phase modifiers on boron removal by solvent extraction using 1,3 diolic compounds," $J$. Chemical Technology and Biotechnology 89(6), 858-865. DOI: 10.1002/jctb.4322

Fujita, Y., Hata, T., Nakamaru, M., Iyo, T., Yoshino, T., and Shimamura, T. (2005). "A study of boron adsorption onto activated sludge," Bioresource Technology 96(12), 1350-1356. DOI: 10.1016/j.biortech.2004.11.008

GB/T 455 (2002). "Paper and board-determination of tearing resistance," Standardization Administration of China, Beijing, China. 
GB/T 22898 (2008). "Paper and board-determination of tensile properties-Constant rate of elongation method," Standardization Administration of China, Beijing, China.

Goldberg, S. (2005). "Inconsistency in the triple layer model description of ionic strength dependent boron adsorption," Journal of Colloid and Interface Science 285(2), 509517. DOI: 10.1016/j.jcis.2004.12.002

Inukai, Y., Tanaka, Y., Matsuda, T., Mihara, N., Yamada, K., Nambu, N., Itoh, O., Doi, T., Kaida, Y., and Yasuda, S. (2004). "Removal of boron (III) by Nmethylglucamine-type cellulose derivatives with higher adsorption rate," Analytica Chimica Acta 511(2), 261-265. DOI: 10.1016/j.aca.2004.01.054

Kabay, N., Yilmaz-Ipek, I., Soroko, I., Makowski, M., Kirmizisakal, O., Yag, S., Bryjak, M., and Yuksel, M. (2009). "Removal of boron from Balcova geothermal water by ion exchange-microfiltration hybrid process," Desalination 241(1-3), 167-173. DOI: 10.1016/j.desal.2007.10.100

Liu, H., Qing, B., Ye, X., Li, Q., Lee, K., and Wu, Z. (2009). "Boron adsorption by composite magnetic particles,” Chemical Engineering Journal 151(1-3), 235-240. DOI: 10.1016/j.cej.2009.03.001

Liu, J., Zhu, X., Zhang, H., Wu, F., Wei, B., and Chang, Q. (2018). "Superhydrophobic coating on quartz sand filter media for oily wastewater filtration," Colloids and Surfaces A: Physicochemical and Engineering Aspects 553, 509-514. DOI: 10.1016/j.colsurfa.2018.06.007

Lyu, J., Zeng, Z., Zhang, N., Liu, H., Bai, P., and Guo, X. (2017). "Pyrocatecholmodified resins for boron recovery from water: Synthesis, adsorption and isotopic separation studies," Reactive and Functional Polymers 112, 1-8. DOI: 10.1016/j.reactfunctpolym.2016.12.016

Meng, J., Cao, J., Xu, R., Wang, Z., and Sun, R. (2016). "Hyperbranched grafting enabling simultaneous enhancement of the boric acid uptake and the adsorption rate of a complexing membrane," Journal of Materials Chemistry A 4(30), 11656-11665. DOI: $10.1039 / \mathrm{c} 6 \mathrm{ta02348g}$

Miyazaki, Y., Matsuo, H., Fujimori, T., Takemura, H., Matsuoka, S., Okobira, T., Uezu, K., and Yoshimura, K. (2008). "Interaction of boric acid with salicyl derivatives as an anchor group of boron-selective adsorbents," Polyhedron 27(13), 2785-2790. DOI: 10.1016/j.poly.2008.06.007

Nable, R. O., Banuelos, G. S., and Paull, J. G. (1997). "Boron toxicity," Plant and Soil 193(1-2), 181-198. DOI: 10.1023/A:1004272227886

Nishihama, S., Sumiyoshi, Y., Ookubo, T., and Yoshizuka, K. (2013). "Adsorption of boron using glucamine-based chelate adsorbents," Desalination 310, 81-86. DOI: 10.1016/j.desal.2012.06.021

Ozturk, N., and Kavak, D. (2005). "Adsorption of boron from aqueous solutions using fly ash: batch and column studies," Journal of Hazardous Materials 127(1-3), 81-88. DOI: 10.1016/j.jhazmat.2005.06.026

Peak, D., Luther, G. W., and Sparks, D. L. (2003). "ATR-FTIR spectroscopic studies of boric acid adsorption on hydrous ferric oxide," Geochimica et Cosmochimica Acta 67(14), 2551-2560. DOI: 10.1016/s0016-7037(03)00096-6

Sahin, S. (2002). "A mathematical relationship for the explanation of ion exchange for boron adsorption," Desalination 143(1), 35-43. DOI:10.1016/S0011-9164(02)00219-9

Sauperl, O., Kostic, M., Milanovic, J., and Zemljic, L. F. (2015) "Chemical binding of chitosan and chitosan nanoparticles onto oxidized cellulose," Journal of Engineered Fibers and Fabrics 10(2), 70-77. DOI: 10.1177/155892501501000208 
Sun, L., Huang, J., Liu, H., Zhang, Y., Ye, X., Zhang, H., Wu, A., and Wu, Z. (2018). "Adsorption of boron by CA@KH-550@EPH@NMDG (CKEN) with biomass carbonaceous aerogels as substrate," Journal of Hazardous Materials 358, 10-19. DOI: $10.1016 /$ j.jhazmat.2018.06.040

Tang, H. R., Covington, A. D., and Hancock, R. A. (2003). "Structure-activity relationships in the hydrophobic interactions of polyphenols with cellulose and collagen," Biopolymers 70(3), 403-413. DOI: 10.1002/bip.10499

Tural, B. (2010). "Separation and preconcentration of boron with a glucamine modified novel magnetic sorbent," Clean Soil Air Water 38(4), 321-327. DOI: 10.1002/clen.201000031

Turek, M., Dydo, P., Trojanowska, J., and Campen, A. (2007). “Adsorption/coprecipitation-reverse osmosis system for boron removal," Desalination 205(1-3), 192-199. DOI: 10.1016/j.desal.2006.02.056

Vatankhah-Varnoosfaderani, M., Hashmi, S., GhavamiNejad, A., and Stadler, F. J. (2014). "Rapid self-healing and triple stimuli responsiveness of a supramolecular polymer gel based on boron-catechol interactions in a novel water-soluble musselinspired copolymer," Polymer Chemistry 5(2), 512-523. DOI: 10.1039/C3PY00788J

Xia, N. N., Rong, M. Z., and Zhang, M. Q. (2016). "Stabilization of catechol-boronic ester bonds for underwater self-healing and recycling of lipophilic bulk polymer in wider pH range," Journal of Materials Chemistry A 4(37), 14122-14131. DOI: $10.1039 / \mathrm{c} 6 \mathrm{ta} 05121 \mathrm{a}$

Xiao, M., and Hu, J. (2017). "Cellulose/chitosan composites prepared in ethylene diamine/potassium thiocyanate for adsorption of heavy metal ions," Cellulose 24(6), 2545-2557. DOI: 10.1007/s10570-017-1287-9

Yazicigil, Z., and Oztekin, Y. (2006). "Boron removal by electrodialysis with anionexchange membranes," Desalination 190(1-3), 71-78. DOI: 10.1016/j.desal.2005.07.016

Yilmaz, I., Kabay, N., Yuksel, M., Holdich, R., and Bryjak, M. (2007). "Effect of ionic strength of solution on boron mass transfer by ion exchange separation," Separation Science and Technology 42(5), 1013-1029. DOI: 10.1080/01496390701206181

Zhang, X., Wang, J., Chen, S., Bao, Z., Xing, H., Zhang, Z., Su, B., Yang, Q., Yang, Y., and Ren, Q. (2017). "A spherical N -methyl-d -glucamine-based hybrid adsorbent for highly efficient adsorption of boric acid from water," Separation and Purification Technology 172, 43-50. DOI: 10.1016/j.seppur.2016.08.002

Article submitted: May 9, 2019; Peer review completed: July 21, 2019; Revised version received: July 30, 2019; Accepted: July 31, 2019; Published: August 7, 2019.

DOI: $10.15376 /$ biores.14.4.7734-7750 